\title{
MODIFICATION OF SURFACE OF BASALT FABRIC ON PROTECTING AGAINST HIGH TEMPERATURES BY THE METHOD OF MAGNETRON SPUTTERING
}

\author{
Pamela Miśkiewicz'1, Iwona Frydrych¹, Wojciech Pawlak², Agnieszka Cichocka1 \\ ${ }^{1}$ Lodz University of Technology, Faculty of Material Technologies and Textile Design, Institute of Architecture of Textiles, Lodz, Poland, \\ e-mail: pamela_miskiewicz@wp.pl, \\ 2Lodz University of Technology, Faculty of Mechanical Engineering, Institute of Materials Engineering, Lodz, Poland
}

\begin{abstract}
:
Basalt fibers and fabrics made of these are characterized by excellent thermal and mechanical properties. Therefore, basalt fabrics, due to a good resistance to high temperatures, are frequently applied in the personal protection equipment (PPE). In order to improve their thermal properties and, above all, the contact heat resistance, the process of physical vapor deposition was proposed. The process of Physical Vapor Deposition (PVD) involves producing a coating on a specific substrate as a result of physical deposition of molecules, ions or atoms of the selected chemical compounds. The method selected for the test is the magnetron sputtering. It involves depositing a uniform film of chromium on the surface of the basalt fabric. In order to improve the thermal properties - especially the contact heat resistance, two values of thickness of the chromium layer deposited on the basalt fabric surface were adopted for the test. Covering $1 \mu \mathrm{m}$ and $5 \mu \mathrm{m}$ with the chromium layer did not fulfil the expectations and the research will be continued.
\end{abstract}

\section{Keywords:}

Basalt fibers, basalt fabrics, magnetron sputtering, good resistance to high temperatures

\section{Introduction}

Basalt fabrics and products made of these - due to their properties such as non-flammability, good resistance to high temperatures, safety in use, good fatigue resistance as well as the resistance to UV radiation, contamination and chemicals - are used in the personal protection equipment that protects against hot work environments.[1,2] So far, materials such as fabrics made of glass fibers, aluminized fabrics, fabrics and nonwovens made of aramid fibers - aluminized and nonaluminized, or aramid fibers combined with cotton, wool and cotton fabrics with a non-flammable impregnation and heatresistant leathers, have been the most frequently used in the construction of gloves designed to protect against thermal factors.[3]

Until now, the Central Institute for Labor Protection-National Research Institute, in cooperation with the Lodz University of Technology, have been dealing with a similar research topic, while realizing the project of acronym BAGLO, which is aimed at developing a new construction of protective gloves, designed to protect against heat, but simultaneously ensuring the protection against mechanical factors and characterized by a good performance. In the construction of new type of protective gloves, some model solutions involving fabrics made of basalt fibers were applied as well as with modifications of basalt fabrics by coating with an aluminum foil. In order to obtain aluminized basalt fabrics, a polyester foil was used, which was covered on both sides with several millimeter layers of aluminum. The textile material with the aluminized foil was joined by gluing. For this purpose, two types of adhesive mean have been selected. The first was a multi-component adhesive mean insoluble in water and based on a mixture of epoxy resins; the second was a dispersion adhesive formed on aqueous dispersions of synthetic resins and polyurethanes, containing no organic solvents. As a result of the conducted research, concerning thermal and mechanical properties of the tested material, it was found that the selected variants of aluminized basalt fabric cannot be applied in the palm part of the protective glove due to their insufficient resistance to contact heat. They were, however, successfully used in the outer part of the glove. An additional disadvantage of the coating was cracking and abrasion of the applied layer during the making-up processes. Therefore, it was not as good as expected.

Due to the planned application of the modified basalt fabrics in the palm part of the protective glove, the main task of our research is to improve their resistance to when they come in contact with heat and ensure that after cracking, basalt fibers do not cause the skin irritation.[4-6]

Our research continues on the optimization of the construction of protective gloves, with the use of new materials and modern technologies, which can ensure high strength and good barrier properties of the final product.[3]

In order to improve thermal properties, and above of all, the resistance to contact heat, microstructural coatings were deposited on the surface of the basalt fabric. To modify the basalt fabric, the Physical Vapor Deposition process (PVD) was selected, which is based on creating the coating on a specific substrate as a result of physical deposition of atoms, molecules or ions of specific chemical compounds. The 
process of Physical Vapor Deposition (PVD) can be carried out by sputtering, vaporization and spraying.[7]

So far, the research has been carried out with the application of the magnetron sputtering technique to produce an antibacterial coating on the fabric with an admixture of cotton. The usual tests used silver, copper, platinum and gold. It has been found that copper is the most effective protection against bacteria and fungi. Silver was also effective against bacteria, however, in the case of fungi, its effectiveness turned out to be insufficient. Other metal layers didn't produce satisfactory efficacy.[8]

Jiang, Qin, Guo and Zhang worked on the surface functionalization of polyester fibers with a nano-structured silver coating using the magnetron sputtering method to broaden its applications. Surface characteristics are made on a scanning electron microscope. The results showed that polyester fabrics with a deposited silver coating have excellent protection against ultraviolet radiation, show very good hydrophobicity and have a good antibacterial effect. As a result of the study, it was found that the surface treatment using silver nanoparticles and the method that was used, and thus, magnetron sputtering is a very promising method for obtaining multifunctional fabrics.[9]

Until now, the surface modification of fabrics using different elements and magnetron sputtering methods have been carried out mainly to improve the antibacterial properties.

\section{Experimental}

\subsection{Materials}

Different types of basalt fabrics were selected for the tests - with the silicone coating on both sides, reinforced with a stainlesssteel wire and modified with chromium as well as a fabric made of Kevlar fibers. The fabrics differed in mass per unit area, weave and thickness. Some materials were obtained from producers (Ip. 1-4 form Table 1), while some were prepared by us.

\subsection{Methods}

\subsubsection{Magnetron sputtering}

Magnetron sputtering technique was chosen to modify the surface of basalt fabrics. The method is based on sputtering the material, which is the substrate of the produced coating, by using gas ions obtained in the area between the plasma and the insert. The sputtered ions pass through the plasma, undergoing the ionization or reactions with ions or atoms of reactive gas, leading to the deposition of coating on the material surface.[10-13]

The magnetron sputtering technique (Fig. 1.) mainly uses a magnetic field and a polarized substrate. The main element of the device - the magnetron - is responsible for glow discharges occurring in the crossed magnetic field.

Table 1. Characteristics of selected materials

\begin{tabular}{|c|c|c|c|c|c|c|}
\hline Lp & Fabric type & Fabric photo & $\begin{array}{c}\text { Mass per unit area } \\
{\left[\mathrm{g} / \mathrm{m}^{2}\right]}\end{array}$ & Weave & $\begin{array}{l}\text { Thickness } \\
\text { [mm] }\end{array}$ & Symbol \\
\hline 1 & $\begin{array}{l}\text { Fabric made of basalt } \\
\text { fibers }\end{array}$ & & 398 & twill & 0,55 & B \\
\hline 2 & $\begin{array}{l}\text { Fabric made of Kevlar } \\
\text { fibers }\end{array}$ & & 200 & plain & 0,30 & K \\
\hline 3 & $\begin{array}{l}\text { Fabric made of basalt } \\
\text { fibers, with a silicone } \\
\text { coating on both sides }\end{array}$ & & 304 & plain & 0,28 & BS \\
\hline 4 & $\begin{array}{l}\text { Fabric made of basalt } \\
\text { fibers, with a silicone } \\
\text { coating on both } \\
\text { sides reinforced with } \\
\text { stainless steel wire }\end{array}$ & & 477 & plain & 0,43 & BDS \\
\hline 5 & $\begin{array}{l}\text { Basalt fabric modified } \\
\text { with a chromium } \\
\text { coating of the thickness } \\
\text { of } 1 \mu \mathrm{m} \text { and } 5 \mu \mathrm{m} \text {. }\end{array}$ & & 398 & twill & 0,55 & $\begin{array}{l}\text { MB } 1 \mu \mathrm{m} \\
\text { MB } 5 \mu \mathrm{m}\end{array}$ \\
\hline
\end{tabular}




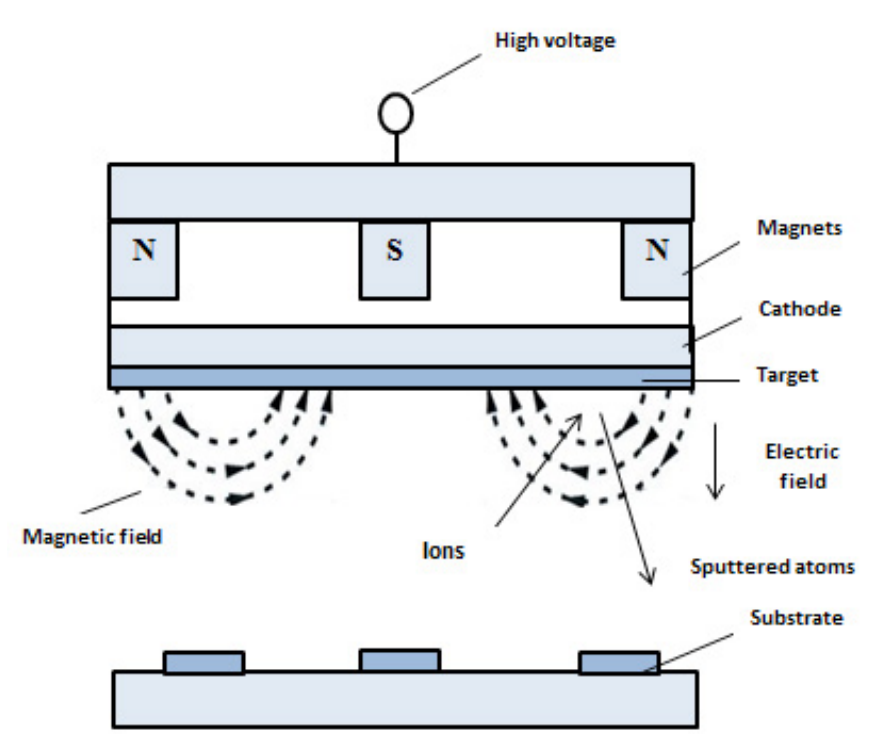

Figure 1. Magnetron sputtering schematic diagram ${ }^{[10]}$

Coatings obtained with this technique should be characterized by a strong bonding with the substrate. They should also improve tribological, anticorrosion and decorative properties of products, which are used under different conditions; and moreover, they should not cause a deterioration of mechanical properties of the substrate.

The magnetron sputtering method was selected due to the material versatility, application flexibility and ability to apply layers on substrates of various sizes and properties. In addition, the proposed method is used for industrial production. ${ }^{[8-11]}$

Some materials were obtained from producers (Ip. 1-4 form Table 1), while some were prepared by us.

The device used for coatings with the process of physical gasphase deposition was used to deposit the chromium coatings.

URM 079 device - a multi-source, hybrid industrial device was used to deposit the coatings (Fig.2). The presented URM 079 device is located at the Institute of Materials Engineering at the Lodz University of Technology.

The stand consists of the following subassemblies:

- vacuum chamber,

- a set of vacuum pumps,

- mixer for working gases,

- control cabinet for the set of pumps and vacuum valves,

- electric power box,

- magnetron power supply.

A chromium coating with a thickness of $1 \mu \mathrm{m}$ and $5 \mu \mathrm{m}$ was deposited on the surface of the basalt fiber fabric.

\subsubsection{Analysis of coating thickness on the scanning electron microscope}

Analysis of coating thickness and determination of the content of individual elements on the surface of basalt fabric as a

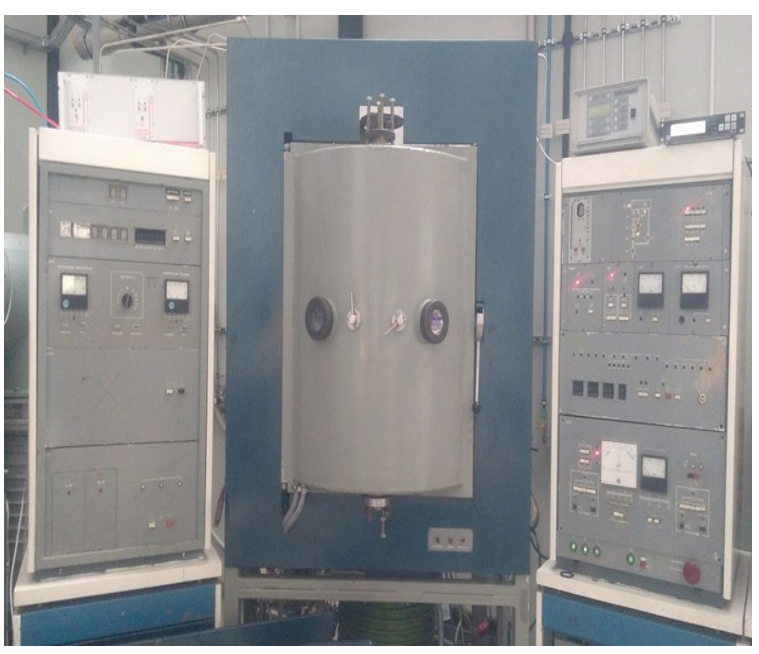

Figure 2. URM stand for coatings deposition by PVD method

result of the coating deposition were carried out on the JOEL scanning electron microscope, model JSM-6610 LV (Fig.3, Table 2) equipped with special software EDS AZtecEnergy owned by the Institute of Materials Science and Engineering of Lodz University of Technology.

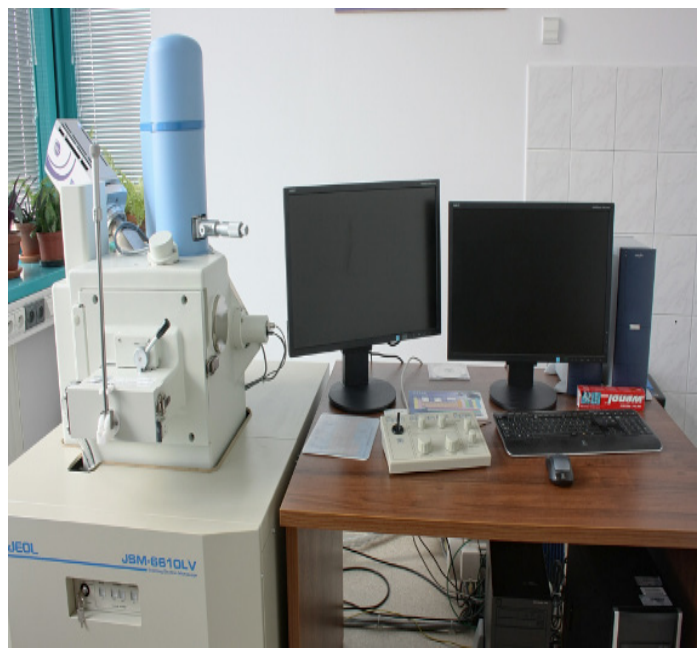

Figure 3. Scanning electron microscope

Table 2. Technical data of the scanning electron microscope

\begin{tabular}{|c|c|}
\hline \multicolumn{2}{|c|}{ Technical data } \\
\hline $\mathrm{HV}$ resolution mode & $\begin{array}{c}3,0 \mathrm{~nm}(30 \mathrm{kV}), 8 \mathrm{~nm}(3 \mathrm{kV}), 15 \\
\mathrm{~nm}(1 \mathrm{kV})\end{array}$ \\
\hline Magnification & $" \times 5$ to $\times 30000 "$ \\
\hline Automatic functions & Sharpness, brightness, contrast \\
\hline Maximum sample & $200 \mathrm{~mm}$ dimeter \\
\hline Image format & BMP, TIFF, JPEG \\
\hline
\end{tabular}

\subsubsection{Resistance to contact heat on the OTI device}

Resistance to contact heat was tested according to the standard PN-EN ISO 12127-1: 2016,[14] using the OTI device for testing the thermal insulation (Fig. 4), for contact temperatures of 


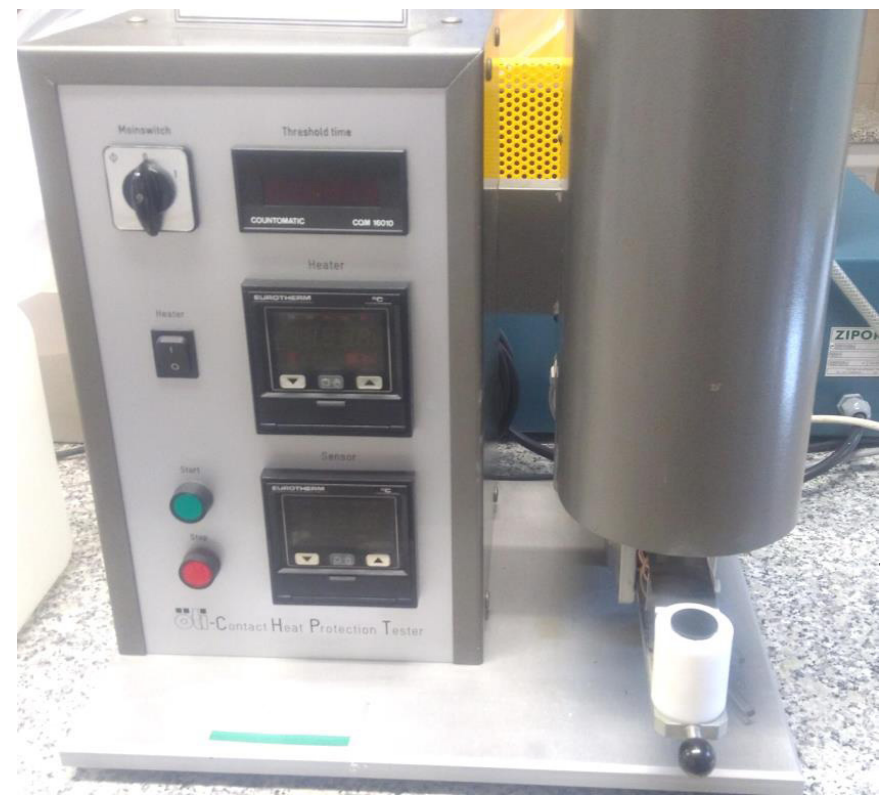

Figure 4. OTI device owned by the Central Institute for Labor Protection-National Research Institute

The standard PN-EN 407:2007 defines the resistance ranges to contact heat, and 4 efficiency levels, to which gloves are classified based on laboratory tests. The efficiency levels are shown in Table 3.[15]

Table 3. Efficiency levels for the resistance to contact heat according to standard PN-EN 407:2007[15]

\begin{tabular}{|c|c|c|}
\hline $\begin{array}{c}\text { Efficiency } \\
\text { levels }\end{array}$ & $\begin{array}{c}\text { Contact Temperature } \\
\text { TC } \\
{\left[{ }^{\circ} \mathbf{C} \text { ] }\right.}\end{array}$ & $\begin{array}{c}\text { Threshold time } \\
\text { period tt } \\
\text { [s] }\end{array}$ \\
\hline 1 & 100 & $\geq 15$ \\
\hline 2 & 250 & $\geq 15$ \\
\hline 3 & 350 & $\geq 15$ \\
\hline 4 & 500 & $\geq 15$ \\
\hline
\end{tabular}

a

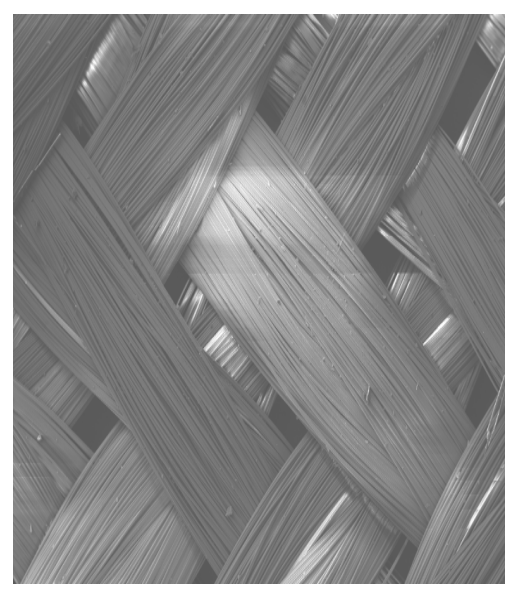

\section{Results and discussion}

From the scanning electron microscope (SEM), we obtained the photographs (Figure 5) showing the surface of the basalt fabric modified by depositing chromium layers of two values of thickness ( 1 and $5 \mu \mathrm{m})$.

Quantitative analysis of the content of individual elements on the surface of the basalt fabric (Figure 6-8 and Table 4-5) coated with the chromium was also done on an SEM. Below in Figure 7, some images obtained directly from the microscope are presented, followed by a detailed analysis of the percentage content of individual elements present in the coatings deposited on the surface of the basalt fabric ( Figure 6 and 8 ).

The following colors presented in Figure 6 correspond to the particular chemical elements occurring on the surface of basalt fabric modified with a $1 \mu \mathrm{m}$-thick chromium layer: Aluminum blue, Silicon - navy, Oxygen - red, Calcium - green.

The percentage content of individual elements is shown in Table 4 below:

Table 4. Percentage of individual elements in $1 \mu \mathrm{m}$ coating deposited on the surface of basalt fabric

\begin{tabular}{|c|c|}
\hline Element & Percentage [\%] \\
\hline $\mathbf{O}$ & 80.33 \\
\hline $\mathbf{A l}$ & 10.38 \\
\hline $\mathbf{S i}$ & 22.58 \\
\hline $\mathbf{C a}$ & 4.92 \\
\hline $\mathbf{C r}$ & 0.28 \\
\hline
\end{tabular}

Due to the significant content of oxygen $80 \%$ and silicon $23 \%$, and the low content of chromium $-0.28 \%$ in the deposited coating, the thickness of the chromium coating was increased. Additionally, the aim of the analysis was checking the adhesion of coating to the base of the basalt fabric.

Figure 5. Photographs of basalt fabric and measurements of different coating thickness made on the SEM a) photo of the basalt fabric of twill weave and mass per unit area $398 \mathrm{~g} / \mathrm{m}^{2}$ without coating, b) microscopic view of the measurement of the $1 \mu \mathrm{m}$ coating deposited on the surface of the basalt fabric, $\mathrm{c}$ ) microscope view of the measurement of the $5 \mu \mathrm{m}$ coating deposited on the surface of the basalt fabric 

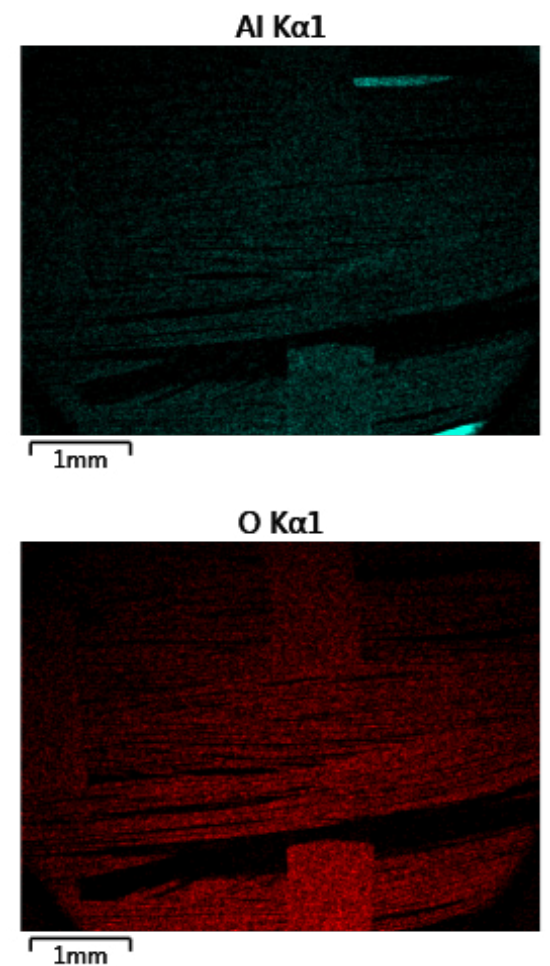

Si K $\alpha \mathbf{l}$

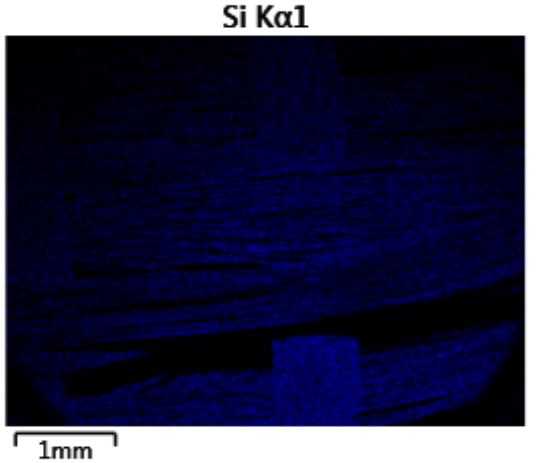

$\mathrm{Ca} K \alpha \mathbf{l}$

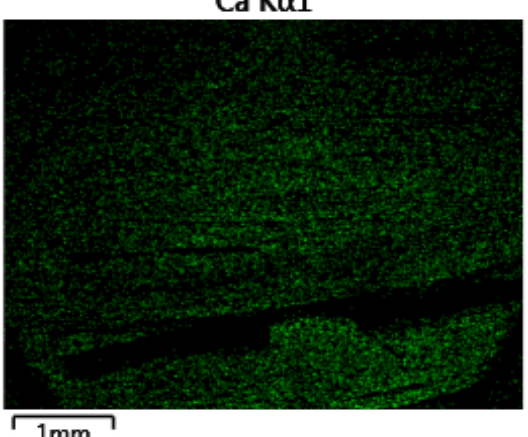

$\longdiv { 1 \mathrm { mm } }$

Figure 6. Colors corresponding to particular chemical elements occurring on the surface of a modified basalt fabric with the $1 \mu \mathrm{m}$ of chromium coating

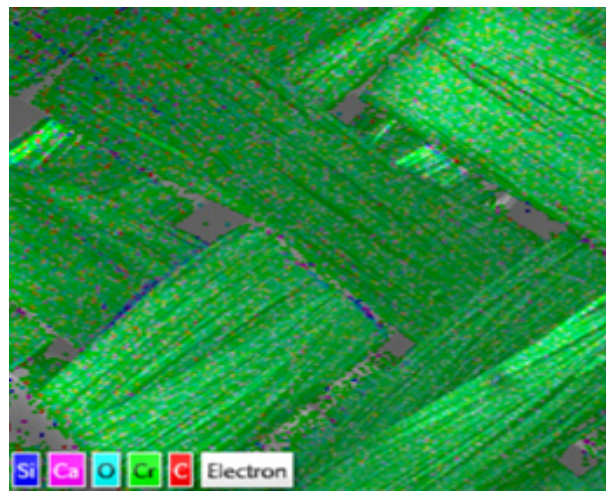

Figure 7. View of $5 \mu \mathrm{m}$ chromium layer deposited on the surface of basalt fabric

The following colors presented in Figure 8 correspond to the particular chemical elements occurring on the surface of the basalt fabric modified with a $5 \mu$ m-thick chromium layer: Chrome - green, Oxygen - blue, Carbon - red, Calcium violet. Carbon and calcium in Figure 9 are hardly visible due to the low content of these elements in the coating.

The percentage content of individual elements is shown in Table 5 below:

For the coating thickness of $5 \mu \mathrm{m}$, the chromium content is $98.8 \%$, what means that the entire surface of the basalt fabric has been covered with chrome.

In tables 6-7 and Figure 9, the measurement results of resistance to contact heat for two different contact temperatures are presented, for all the selected variants of basalt fabrics.

The highest resistance to contact heat for the contact temperature of $250^{\circ} \mathrm{C}$ was observed in the case of the basalt fabric coated with silicone on both sides and reinforced with the stainless-steel wire (BDS), while the lowest for the unmodified basalt fabric (B). Due to the fact that in all the tested samples, the efficiency level was 0 , it was decided to decrease the contact temperature to $100^{\circ} \mathrm{C}$. The results of the contact heat resistance for the contact temperature $100^{\circ} \mathrm{C}$ are given in Table 7.

Table 5. Percentage of individual elements in $5 \mu \mathrm{m}$ coating deposited on the surface of basalt fabric

\begin{tabular}{|c|c|}
\hline Element & Percentage [\%] \\
\hline C & 2.50 \\
\hline O & 3.06 \\
\hline Ca & 0.44 \\
\hline Cr & 98.77 \\
\hline
\end{tabular}



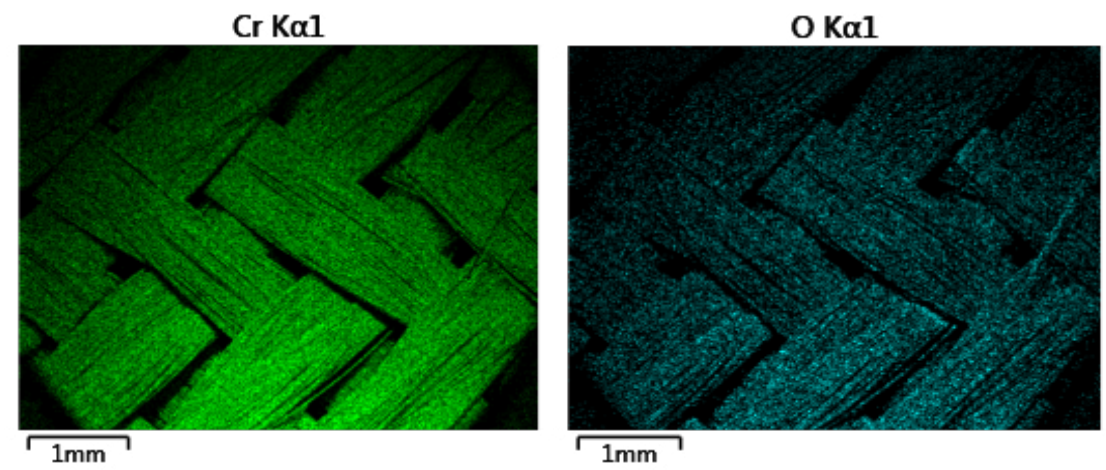

C K $\alpha 1 \_2$

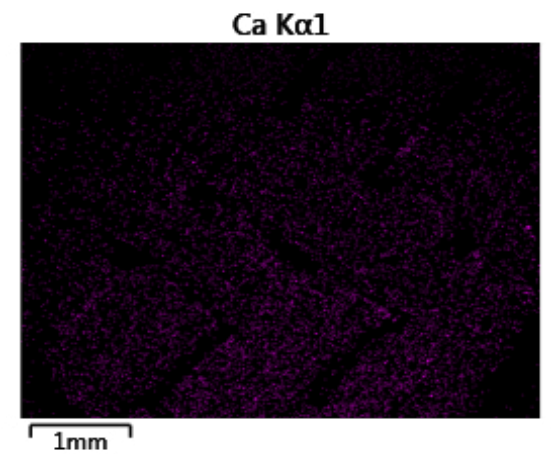

Figure 8. Colors corresponding to particular chemical elements occurring on the surface of modified basalt fabric with the $5 \mu \mathrm{m}$ of chromium coating

Table 6. Measurement results of contact heat resistance for the contact temperature of $250^{\circ} \mathrm{C}$

\begin{tabular}{|c|c|c|c|c|c|c|}
\hline & B & K & BS & BDS & MB1 $\boldsymbol{\mu m}$ & MB 5 $\boldsymbol{\mu m}$ \\
\hline \multirow{2}{*}{$\begin{array}{c}\text { Resistance to contact heat } \\
250^{\circ} \mathrm{C}, \mathrm{t}_{\mathrm{t}}[\mathrm{s}]\end{array}$} & 4.40 & 4.55 & 6.50 & 8.27 & 4.74 & 4.75 \\
\cline { 2 - 8 } & 4.24 & 4.78 & 6.60 & 8.07 & 4.66 & 4.72 \\
\hline $\bar{x}$ & 4.28 & 4.64 & 6.40 & 8.8 & 4.59 & 4.73 \\
\hline SD & $4,31 \approx 4$ & $4,66 \approx 5$ & $6,50 \approx 7$ & $8,38 \approx 8$ & $4,66 \approx 5$ & $4,73 \approx 5$ \\
\hline $\mathrm{SD}^{2}[\%]$ & 0.08 & 0.12 & 0.10 & 0.38 & 0.08 & 0.02 \\
\hline Efficiency level & 1.86 & 2.58 & 1.54 & 4.53 & 1.72 & 0.42 \\
\hline
\end{tabular}

Table 7. Measurement results of contact heat resistance for the contact temperature of $100^{\circ} \mathrm{C}$

\begin{tabular}{|c|c|c|c|c|c|c|}
\hline & B & $\mathbf{K}$ & BS & BDS & MB1 $\mu \mathrm{m}$ & MB $5 \mu \mathrm{m}$ \\
\hline \multirow{3}{*}{$\begin{array}{l}\text { Resistance to contact heat } \\
\qquad 100^{\circ} \mathrm{C}, \mathrm{t}_{\mathrm{t}}[\mathrm{s}]\end{array}$} & 10.95 & 10.88 & 12.60 & 15.40 & 11.91 & 12.62 \\
\hline & 10.69 & 10.98 & 12.30 & 15.55 & 11.67 & 12.26 \\
\hline & 10.81 & 10.83 & 12.60 & 15.50 & 11.40 & 12.62 \\
\hline $\bar{x}$ & $10,82 \approx 11$ & $10,90 \approx 11$ & $12,50 \approx 13$ & $15,52 \approx 16$ & $11,66 \approx 12$ & $12,50 \approx 13$ \\
\hline SD & 0.13 & 0.08 & 0.17 & 0.10 & 0.21 & 0.21 \\
\hline $\mathrm{SD}^{2}[\%]$ & 1.2 & 0.73 & 1.36 & 0.64 & 1.8 & 1.68 \\
\hline Efficiency level & 0 & 0 & 0 & 1 & 0 & 0 \\
\hline
\end{tabular}

In the case of resistance to contact heat for the contact temperature of $100^{\circ} \mathrm{C}$, the highest value was obtained for the unmodified basalt fabric coated with silicone on both sides and reinforced with stainless steel wire (BDS), and the lowest one for the Kevlar fabric of thickness $0.3 \mathrm{~mm}$. Only for the BDS sample, the achieved efficiency level was 1 . In rest of the cases, the samples didn't fulfill the requirement, but it should be noted that the chromium coating increased the resistance to contact heat a little in comparison to the unmodified basalt fabric (B). Probably the thickness of coatings ( 1 and $5 \mu \mathrm{m}$ ) was too small to achieve the expected result. Therefore, the research will be continued with thicker than $5 \mu \mathrm{m}$ chromium coatings. 
Figure 9. Comparison of contact heat resistance for all tested variants for contact temperatures of $250^{\circ} \mathrm{C}$ and $100^{\circ} \mathrm{C}$

\section{Summary}

The highest resistance to contact heat for the contact temperatures of $250^{\circ} \mathrm{C}$ and $100^{\circ} \mathrm{C}$ was observed in the case of basalt fabric coated with silicone on both sides and reinforced with stainless steel wire (BDS), and only this fabric reached the 1st level of efficiency at $100^{\circ} \mathrm{C}$. As shown in Tables $6-7$ and Figure 9, similar resistance results for both temperatures were obtained for basalt fabrics coated with silicone on both sides (BS) and basalt fabrics modified with $5 \mu \mathrm{m}$ chromium layer (MB $5 \mu \mathrm{m})$. Slightly worse results were observed for the basalt fabric modified with $1 \mu \mathrm{m}$ chromium layer (MB $1 \mu \mathrm{m})$. It should be noted that the Kevlar fabric $(\mathrm{K})$ obtained slightly lower values of resistance to contact heat compared to the unmodified basalt fabrics coated with silicone on both sides (BS), although both fabrics had the same thickness of about $0.3 \mathrm{~mm}$, but on the same level as the unmodified basalt fabric (B), which was much thicker. None of the tested fabrics achieved the 1st level of efficiency for resistance to contact heat at the temperature of $250^{\circ} \mathrm{C}$.

\section{CONCLUSIONS}

On the basis of the experiment carried out, the following conclusions can be drawn out;

1. As a result of the modification of the basalt fabric by the magnetron sputtering with the use of chromium, a slight improvement was observed in the contact heat resistance in comparison to the basic (unmodified) basalt fabric.

2. The modification was carried out to check the adhesion of the deposited coating to the surface of basalt fabric, and to analyze the influence of coating thickness on the change in contact heat resistance. The thicker the layer of chromium on the basalt fabric, the better is the resistance to contact heat.

3. These were preliminary studies, in which it was found that metals cannot significantly improve the resistance to contact heat. Chromium was chosen to assure a good radiation heat resistance. Therefore, the next step will be the deposition on the surface of basalt fabric a layer of zirconium oxide with a much larger thickness of approximately $10 \mu \mathrm{m}$.

4. Kevlar fabric used in the construction of the palm part of gloves protecting against high temperatures demonstrates similar resistance to contact heat as the chromium-modified basalt fabric ay contact temperature of $250^{\circ} \mathrm{C}$; however, the Kevlar fabric selected for testing is characterized by much lower thickness.

5. The highest resistance to contact heat for the contact temperatures of $250^{\circ} \mathrm{C}$ and $100^{\circ} \mathrm{C}$ was observed in the case of unmodified basalt fabric coated with silicone on both sides and reinforced with stainless steel wire introduced in every 5 th weft thread (BDS), which had the largest mass per ten unit area.

6. Further research will be carried out to increase the thickness of the chromium layer. If the tests do not meet the expectations regarding resistance to contact heat, the modification will be carried out using oxides.

\section{ACKNOWLEDGEMENTS}

The results were presented at the 1st National Scientific Conference "Innovative Faces of Textile Industry".

\section{References}

[1] Frydrych, I. (2008). Study of clothing materials - raw materials for protective clothing, Part I Clothing for fire protection. (In Polish) Przegląd Włókienniczy-Włókno Odzież Skóra, Issue.6, pp.29-33, 2008.

[2] Miśkiewicz, P., Frydrych, I. (2017). Considerations on modifying basalt fabrics protecting against the thermal radiation. In World Scientific News An International Scientific Journal, vol 76, pp. 85-90.

[3] Majchrzycka, K., Pościk, A. . (2007). Selection of individual protection means. (In polish), Warsaw, pp.244-250.

[4] Hrynyk, R., Frydrych, I. (2015). Study on textile assemblies with aluminized basalt fabrics destined for protective gloves. In International Journal of Clothing Science and Technology, vol 27 (5).

[5] Hrynyk, R., Frydrych, I., Stefko, A., Irzmańska, E. (2012). Thermal properties of aluminized and non-aluminized basalt fabrics. In Textile Research Journal, 2012.

[6] Hrynyk, R. (2013). Basalt fabrics - evaluation of the possibility of applying in gloves protecting against thermal factors. (In polish), Bezpieczeństwo Pracy, Issue 2, pp. 2225.

[7] Knotek, O., Löffler, F., Krämer G. (1993). Process and advantage of multicomponent and multilayer PVD coatings. Surface and Coatings Technology, Vol. 59, Issues 1-3, pp. 14-20.

[8] Yip, J., Jiang, S., Wong, CH. (2009). Characterization of metallic textiles deposited by magnetron sputtering and traditional metallic treatments. Surface and Coatings Technology, Vol. 204, Issue 3, pp. 380-385.

[9] Jiang, S.X., Qin, W.F., Guo, R.H., Zhang, L. (2010). Surface functionalization of nanostructured silver-coated polyester fabric by magnetron sputtering. Surface and Coatings Technology, Vol. 204, Issues 21-22, pp, 3662-3667.

[10] Dobrzański, L.A. . (2009). Shaping the structure and properties of the surfaces of engineering and biomedical materials. (In Polish)Copyright by L.A. Dobrzański, Gliwice, 2009.

[11] Miśkiewicz, P., Frydrych, I., Cichocka, A., Pawlak, W. (2017) Considerations on applying selected techniques of CVD and PVD processes for modifying basalt fabrics used for protective gloves. Monograph Innovations in protective and e- textiles in balance with comfort and ecology, Łódź, Publisher Lodz University of Technology, pp. 120-130. 
[12] Schiller, S., Goedicke, K., Reschke, J., Kirchhoff, V., Schneider, S., Milde, F. (1993). Pulsed magnetron sputter technology. Surface and Coatings Technology, Vol.61, Issues 1-3, pp. 331-337.

[13] Swann S. (1988). Magnetron Sputtering. Physics in Technology, Vol.19.
[14] PN-EN ISO 12127-1: 2016 Clothing that protects against heat and flame. Determination of contact heat penetration through protective clothing or materials intended for it. Part 1: The contact heat produced by the heating cylinder.

[15] PN-EN 407:2007 Gloves protecting against thermal risks (hot and / or fire). 